\title{
Canadá: organizações de aprendizagem no setor público*
}

\author{
Centro Canadense \\ para o Desenvolvimento \\ da Gestão $(C C M D)^{l}$
}

Revista do

Serviço

Público

Ano 52

Número 3

Jul-Set 2001

\section{Introdução}

No mundo inteiro, os governos modernos estão envolvidos com transformações sociais, econômicas e tecnológicas fundamentais. O mundo ficou mais interligado, rápido, diversificado e, conseqüentemente, menos previsível. Isto faz com que o conhecimento o o "poder do intelecto" fiquem mais centrados no cumprimento das responsabilidades de um governo. Quanto mais soubermos e entendermos coletivamente, melhor equipados estaremos para dimensionar as oportunidades e gerenciar os riscos. Ainda assim, apesar do amplo reconhecimento destes acontecimentos, existem relativamente poucas propostas abrangentes para aproveitar o poder do conhecimento.

Esta situação é, de certa forma, compreensível. Em um ambiente que muda rapidamente, qualquer plano detalhado corre o risco de ficar ultrapassado no momento de sua implementação. O simples tamanho de várias organizações públicas torna difícil a administração de mudanças de forma abrangente. Além disso, ainda não está claramente definida a maneira de se gerenciar o conhecimento e o "poder do intelecto", que são bem menos tangíveis do que outras características da vida organizacional. Assim sendo, à medida que o novo ambiente governamental evolui, estamos sendo compelidos a repensar a maneira pela qual a transformação é gerenciada no serviço público de conhecimento intensivo.

Nossas reflexões sobre o assunto estão apenas começando. Felizmente, já dispomos de um discernimento-chave para nos orientar: as organizações se adaptam rapidamente e obtêm melhores resultados quando um aprendizado contínuo é integrado à vida cotidiana das pessoas, em seus ambientes de trabalho.

Centro

Canadense

para o

Desenvolvimento

da Gestão,

Otawa, Canadá.

Contato:

www.ccmd-

ccg.gc.ca

*Relatório apresentado na Conferência do IIAS-IASIA em Atenas, Grécia, julho de 2001. 
Este entendimento é baseado na concepção de que as pessoas mais diretamente afetadas pelas mudanças estão em melhor situação para aproveitar as oportunidades apresentadas pela nova situação. É, portanto, crucial que os servidores públicos reflitam sobre todas as áreas da vida organizacional como uma rica fonte de idéias, invenções e experimentações. Ao mesmo tempo, os servidores públicos devem contribuir com entusiasmo e compartilhar as lições aprendidas, dentro e através dos limites organizacionais. Os dirigentes públicos podem contribuir para que isto aconteça investindo no desenvolvimento intelectual de seu staff e encorajando a investigação compartilhada entre os membros de sua equipe.

O resultado final é freqüentemente chamado de "organização de aprendizagem", ou seja, uma organização que está continuamente apta e disposta a melhorar por meio de um aprendizado contínuo, talento e idéias perspicazes.

Este artigo irá discutir as várias dimensões de uma organização de aprendizagem. Também irá descrever a experiência do serviço público canadense na implementação desta abordagem. O quadro que se apresenta é o de uma abordagem canadense distinta para criar a organização de aprendizagem, uma organização com várias características instigantes.

$\mathrm{O}$ artigo é apresentado em quatro seções. A primeira seção irá descrever os contornos principais de uma organização de aprendizagem - o que é, por que é importante, e como ela é criada. A segunda seção descreve o modelo canadense - suas origens, suas características-chave, e suas perspectivas futuras. A terceira seção enfoca diversas iniciativas futuras que emergem do modelo canadense. Por fim, apresenta-se uma conclusão que resume as lições-chave e proporciona algumas recomendações aos servidores públicos em outras jurisdições.

\section{A organização de aprendizagem}

\section{O que é uma organização de aprendizagem?}

É importante que sejamos claros desde o início sobre o que a expressão "organização de aprendizagem" significa e de onde ela vem. Existem várias razões para isso. Primeiro, porque costumamos pensar normalmente que o aprendizado é algo feito exclusivamente por indivíduos. Em segundo lugar, porque novas palavras de ordem surgem e desaparecem, mas, quase sempre, não oferecem contribuições duradouras. Em alguns casos até criam cepticismo. Portanto, existe uma necessidade de mostrar que a terminologia associada com a organização de aprendizagem é rigorosa e consistente. Finalmente, a organização de aprendizagem é um conceito 
com várias dimensões. Tendo uma visão clara sobre estas dimensões, estaremos mais aptos a ver o potencial de aplicação do conceito.

A informação de que as organizações têm em si características de aprendizado, data de pesquisas acadêmicas conduzidas entre o começo dos anos 60 e o fim dos anos 70. Os pesquisadores exploraram como, em situações em que as organizações se defrontam com desafios, seus membros sistematicamente se questionam no sentido de reduzir a ambigüidade e melhorar a previsibilidade. $\mathrm{O}$ aprendizado, neste sentido, tendia a ser associado aos mecanismos de realimentação que ajudavam uma organização a investigar continuamente os processos internos e o ambiente externo, detectar ameaças e oportunidades emergentes, e seguir o melhor caminho. O termo "aprendizado organizacional" foi criado por Chris Argyris e Donald A. Schön (1978) para descrever como as organizações tiravam lições deste processo de investigação para alcançar os objetivos organizacionais.

Praticamente ao mesmo tempo, pesquisadores também estavam estudando o valor econômico do conhecimento e da especialização. Termos como "recursos humanos" e "vantagens do conhecimento" eram usados para expressar os valores que as organizações recebiam de seus investimentos em educação, treinamento, pesquisa e coleta de inteligência. David McClelland (1974) deu um passo adiante ao olhar para as "competências" específicas que os trabalhadores do conhecimento precisavam ter para prosperar no ambiente de trabalho moderno. Esta pesquisa agora forma a base fundamental do desenvolvimento moderno da carreira, que não pressupõe que a educação formal do indivíduo seja suficiente. Os trabalhadores do conhecimento não fazem uma distinção clara entre a educação e o trabalho; pelo contrário, ambos — educação e trabalho — estão interligados em um compromisso incessante para o crescimento intelectual. Isto é o que normalmente se denomina "aprendizado vitalício".

Tomados conjuntamente, o aprendizado vitalício e o aprendizado organizacional formam os pilares centrais da organização de aprendizagem. O primeiro pilar enfatiza o desenvolvimento intelectual do indivíduo. Uma organização de aprendizagem, no entanto, é mais do que apenas a soma das capacidades de aprendizagens individuais. Portanto, o segundo pilar enfatiza a necessidade dos indivíduos de trabalhar em conjunto (coletivamente), em colaboração mutuamente benéfica. $\mathrm{O}$ conhecimento e o discernimento que resultam disso não permanecem no interior de um só indivíduo, mas são reconhecidos pela organização.

No quarto de século que se passou desde o surgimento dessas idéias, houve um grande desenvolvimento no sentido de elaboração e aperfeiçoamento. A organização de aprendizagem transformou-se em um conceito "guarda-chuva" usado para descrever uma rica série de atividades orientadas para o aprendizado. Essas atividades operam em vários níveis: 
- Aprendizado individual — a organização de aprendizagem promove o aprendizado individual em duas frentes inter-relacionadas.

A primeira frente é o dia-a-dia do trabalho. A cultura organizacional e os sistemas de incentivo são capazes de promover um ethos de curiosidade, de investigação e de reflexão na condução do trabalho diário. Motivadores externos para promover o aprendizado, no entanto, não são suficientes. O ideal seria buscar entender os interesses individuais, os talentos e as aspirações do indivíduo e, assim, alavancar suas disposições intrínsecas para o aprendizado. Mais do que isso, o aprendizado pode ser ampliado pelo desenho do espaço de trabalho que possibilite aos indivíduos uma interação adequada com os colegas, um acesso às informações e às ferramentas necessárias para que possam atuar efetivamente.

A segunda frente é o desenvolvimento pessoal e profissional. Oportunidades para engajarem-se em um aprendizado formal proporcionam uma maneira eficiente para os indivíduos adquirirem grande quantidade de conhecimentos e habilidades sofisticadas. O desafio é o de prover as necessidades ao gosto de um "estilo de aprendizado" particular do indivíduo, ou a maneira pela qual alguém prefere (ou está predisposto a) receber novos conhecimentos. Algumas pessoas preferem o aprendizado em sala de aula, por exemplo, enquanto outros aprendem melhor estudando sozinhos. Uma variedade de novos métodos de ensino está disponível para satisfazer as necessidades individuais do aluno, incluindo o sistema de mentores, o coaching, e o "aprendizado eletrônico" (i.e., métodos que empregam a informação e as tecnologias da comunicação). Finalmente, estas experiências de aprendizado deverão ser envolvidas em uma estratégia de desenvolvimento de carreiras mais ampla. O método da "descrição das competências" permite aos indivíduos identificar as habilidades e o conhecimento de que eles precisam para atuar mais efetivamente a longo prazo. Este é apenas um ingrediente dos "planos de aprendizado" individuais, que projetam metas de desenvolvimento concretas e estão ligados a uma avaliação de desempenho rotineira do indivíduo.

- Aprendizado em grupo - grande parte do conhecimento de uma organização é criada e difundida por meio de atividades de grupo — sejam elas conversas improvisadas, reuniões, eventos especiais, ou interação de equipes. Atividades de resolução conjunta de problemas (tais como seções de brainstorm) atraem diversas pessoas na busca de soluções mutuamente aceitáveis. O diálogo é uma conversação aberta e franca que situa as pessoas em igualdade de condições para compartilhar idéias, preocupações e pontos de vista. $\mathrm{O}$ diálogo também proporciona um meio de se examinar o rigor intelectual e a pertinência de idéias, argumentos e evidências. Grupos virtuais reúnem as pessoas e criam um espaço de trabalho eletrônico comum. Juntos, estes métodos também estimulam uma compreensão compartilhada, uma coesão do espaço de trabalho e um sentimento de objetivo comum. 
- Redes de aprendizado - uma organização não pode aprender de forma significativa se o conhecimento permanecer retido dentro das pessoas. As organizações públicas são, cada vez mais, compelidas a atuar de forma horizontal, já que as questões políticas crescentemente perpassam as estruturas ministeriais tradicionais. Além disso, os especialistas se beneficiam de um contato contínuo com outros especialistas. Todas essas questões enfatizam a importância de se manter redes dentro e entre as organizações. "Comunidades de prática" são grupos de pessoas com interesses, ocupações e especialização compartilhados. Elas se encontram e fazem intercâmbio de conhecimentos em reuniões presenciais (tais como dentro de grupos de estudo e de diálogo) e em "redes virtuais" que facilitam a comunicação pela Internet (por meio de sites, grupos de discussão online e listas de correios eletrônicos). Estas redes podem ser alimentadas através de uma variedade de outros mecanismos horizontais, tais como estágios e projetos interministeriais. As idéias também podem se propagar rapidamente através de uma organização quando uma unidade "fertiliza o todo", trocando os membros de uma unidade com outra durante atividades importantes.

- Infra-estrutura para o aprendizado organizacional - o campo da "administração do conhecimento" surgiu para reter o conhecimento de forma sistemática (incluindo as formas tácitas) e torná-lo mais amplamente disponível em toda a organização. Com ajuda da infra-estrutura tecnológica, que coloca o conhecimento e a informação ao alcance dos trabalhadores, os gerentes do conhecimento ajudam a preservar uma "memória" organizacional e podem assegurar-se de que o conhecimento é usado em seu potencial total. Isto é possível devido ao reforço de um "centro nervoso" organizacional, que inclui elementos como bibliotecas, expertises dentro da organização, aconselhamento de carreira, e "eventos especiais de aprendizado". As tecnologias de aprendizado à distância facilitam o aprendizado dos servidores públicos em regiões distantes. Para os cidadãos, os serviços de "governo eletrônico" proporcionam acesso online a documentos e contatos, ajudando a tornar o serviço público mais transparente.

Este trabalho não representa, de forma alguma, um estudo exaustivo das várias dimensões de uma organização de aprendizagem. No entanto, ele proporciona a definição de algumas características da organização de aprendizagem.

\section{Por que o serviço público deveria seguir este caminho?}

Existe um relativo consenso, na literatura, sobre as razões pelas quais organizações de todos os tipos necessitam transformar-se em organizações de aprendizagem. Alguns dos argumentos mais comuns podem ser resumidos a seguir: 
- As novas tecnologias de informação e de comunicação possibilitam o acesso a uma enorme quantidade de informação e de dados. Os trabalhadores com capacidades intelectuais sofisticadas e com habilidades técnicas (i.e., "trabalhadores do conhecimento") são chamados a extrair o máximo que estas oportunidades proporcionam sem, no entanto, ficar sobrecarregados pela "carga excessiva de informação". Além disso, essas novas tecnologias estão acelerando o ritmo das mudanças e criando canais mais complicados de interdependência entre as pessoas. Formas de organização mais flexíveis e mais responsáveis são necessárias para adaptar-se a este novo ambiente de trabalho de "conhecimento intensivo".

- As sociedades estão se tornando cada vez mais diversificadas, ou seja, diversificadas nos gostos pessoais, na herança étnico-cultural, no estilo de vida, e na situação socioeconômica. Ao mesmo tempo, os cidadãos estão demandando uma maior adaptação de bens e serviços aos desejos e necessidades pessoais. Em todos os países industrialmente avançados, as instituições estão sendo forçadas a satisfazer estas expectativas mais altas dos cidadãos. Aquelas que falham nesse intuito tendem a sofrer uma perda de legitimidade e de autoridade. As instituições (tais como as instituições políticas, os serviços públicos, e as profissões bem estabelecidas) precisam refletir e alavancar esta diversificação para permanecer relevantes. Isto requer a habilidade de entender as questões de diferentes perspectivas, integrar as várias idéias dentro de um "grande quadro" coerente, e compor mensagens persuasivas para uma audiência diversificada.

- A natureza das relações dentro do espaço de trabalho mudou. As formas tradicionais de autoridade de comando e controle, e de microgerenciamento estão se mostrando ineficazes. Os gerentes delegam mais e deles é exigido um repertório de habilidades que incluem o coaching, o mentorato e a capacidade de negociação. Os empregados precisam de habilidades para trabalhar dentro de ambientes fluidos e baseados em equipes, ou dentro de arranjos completamente novos de trabalho (por exemplo, "teletrabalho"). O trabalho perpassa cada vez mais transversalmente a organização, necessitando de novas formas de diminuição de fronteiras nos relacionamentos profissionais. Todas estas mudanças têm criado um espaço de trabalho mais "horizontal" que precisa de novas competências e novas práticas organizacionais. Algumas atividades ficaram sobrecarregadas pelo novo ambiente e exigem habilidades para lidar com o estresse, a carga de trabalho, e o equilíbrio entre trabalho e a vida privada.

- É fato que os recursos intelectuais de uma organização se esgotam, a não ser que sejam constantemente revigorados. Em outras palavras, um empregador não pode esperar lealdade e capacidade auto-sustentável de um empregado se ele simplesmente "minar" o conhecimento e os talentos de sua força de trabalho. 
Estas tendências interligadas afetam organizações de todos os tipos, sejam elas do setor público, do setor privado, ou do terceiro setor (voluntárias e sem fins lucrativos). Existem, contudo, razões mais específicas para que o setor público necessite "aprender a aprender" mais efetivamente.

- Como sublinha Peter Aucoin, é necessário um serviço público altamente profissional para o estabelecimento de um bom governo, dentro de uma sociedade e de um sistema econômico cada vez mais complexos (Aucoin, 2000). O aprendizado está ficando cada vez mais crucial para a promoção do profissionalismo em pelo menos dois pontos. Primeiro, o profissionalismo é realçado através de investimentos ativos em conhecimento e em habilidades profissionais. Segundo, o conhecimento profissional pode ser compartilhado em uma base contínua, através do estabelecimento de redes (tanto dentro de organizações quanto entre organizações, ou, inclusive, governos).

- Uma maior investigação está sendo implementada para que os governos sejam mais abertos, transparentes e responsáveis. Os cidadãos e a mídia demandam garantias mais concretas de que o serviço público está prestando serviços de alto valor. Isto quer dizer que as informações do governo precisam ser postas ao alcance dos cidadãos — através de novas tecnologias eletrônicas ("governo eletrônico") e de um diálogo entre o os servidores públicos e os cidadãos.

- As organizações públicas têm sido forçadas a encontrar maneiras de competir com o setor privado no recrutamento dos poucos talentos remanescentes. Por razões políticas, uma organização pública não pode oferecer salários extremamente altos e "incentivos" exorbitantes. Uma organização pública pode, por outro lado, estimular um sentimento de orgulho no serviço público e fazer investimentos ativos no desenvolvimento pessoal e profissional de um indivíduo. Em decorrência da sua ênfase histórica ao treinamento, as organizações públicas estão bem posicionadas para contribuir para com o crescimento intelectual do trabalhador e para com seu sentimento de realização pessoal.

- Vários serviços públicos em países avançados e industrializados estão enfrentando uma abertura na estrutura de idade de sua força de trabalho. A aposentadoria iminente da geração baby-boom, representada por várias décadas de medidas de austeridade fiscal, põe a capacidade existente de vários governos em risco. As organizações públicas precisam encontrar novas maneiras de preservar suas "memórias" organizacionais e treinar novas gerações para o serviço público.

- As políticas públicas, cada vez mais, perpassam transversalmente as estruturas governamentais tradicionais, as jurisdições governamentais e as fronteiras nacionais. Por exemplo, questões ambientais têm relação com a política industrial, com a política de recursos naturais, com a política de desenvolvimento das exportações, com o turismo, com a proteção 
ambiental, e com o desenvolvimento urbano, para mencionar apenas algumas. As organizações públicas precisam encontrar melhores maneiras para trabalhar horizontalmente em uma base contínua - trocando informação e empenhando-se em colaborações significativas.

Quando considerados como um todo, estes fatores sugerem que a criação de uma organização de aprendizagem é uma prioridade urgente para qualquer serviço público que se empenhe em permanecer relevante. Diante disso, coloca-se uma questão óbvia: que caminho deve ser seguido para a criação de tal organização?

\section{Como se faz para conseguir que uma organização aprenda?}

A organização de aprendizagem é, sobretudo, um ideal a ser perseguido com empenho. Isto não sugere que seja uma abordagem inalcançável. Contudo, o processo de construção de uma organização de aprendizagem é uma longa jornada que requer um compromisso contínuo $\mathrm{e}$, em alguns aspectos importantes, nunca termina por completo.

A troca de administração, neste caso, torna-se um assunto complicado. Uma grande parte se fixa na criação de uma cultura organizacional que promova o desenvolvimento pessoal, o diálogo, o compartilhamento e a investigação. Sabe-se muito pouco a respeito de como se pode influenciar os padrões culturais e as atitudes pessoais. Nós sabemos, no entanto, que os gerentes precisam de um repertório sofisticado de habilidades de liderança e que eles não podem simplesmente impor um caminho a ser seguido e ficar esperando obediência.

Assim como ocorre em qualquer longo empenho, é importante administrar as expectativas sobre o realismo dos pontos decisivos da vida que uma organização pode atingir; caso contrário, o excesso de expectativas pode resultar em ceticismo e desmoralização. Isto é especialmente verdade durante a criação de uma organização de aprendizagem, desde que a implementação tende a envolver, ao mesmo tempo, uma grande quantidade de experimentações, tentativas e erros, e iniciativas bem-sucedidas. As pessoas precisam entender que os retrocessos e os desafios desanimadores são uma oportunidade de aprendizado e uma fonte de inspiração.

A estratégia geral para promover o aprendizado organizacional é uma questão para debate. Alguns sugerem que este objetivo é mais fácil de ser atingido através de uma iniciativa corporativa superior. Um superior (freqüentemente chamado de "funcionário chefe do aprendizado" ou de "funcionário do conhecimento") provê um locus de responsabilidade e de responsabilização. Tal abordagem é tida como a melhor maneira de mobilizar recursos financeiros escassos, remover obstáculos ao aprendizado, e obter aceitação entre os funcionários mais antigos. Outra escola de pensamento sugere que o aprendizado organizacional é melhor criado através de uma 
“incubadora de aprendizado", ou uma unidade à qual é delegada a tarefa de

cultivar iniciativas de aprendizado localizadas e projetos piloto. Outro ponto de vista é o de que o aprendizado organizacional deve ocorrer mais organicamente, com gerentes e unidades empenhando-se em uma disposição diversificada de experimentos através da organização. Capacitando os indivíduos com aquelas competências que promovem o aprendizado organizacional, a colaboração e a inovação se propagam rapidamente pela organização. Na realidade, a maioria das organizações emprega uma combinação destas estratégias. Iniciativas corporativas mais amplas, por exemplo, são particularmente úteis para o desenvolvimento de infra-estruturas e liberação de recursos. Por outro lado, dar poderes aos indivíduos com novas competências promove o aprendizado em níveis pessoal e interpessoal.

Por meio do processo de implementação, a verificação dos resultados permanece um fator importante, embora seja conduzida de maneira ligeiramente diferente. É difícil, e em alguns casos impossível, localizar detalhadamente algumas atividades de aprendizado. Os benefícios do aprendizado nem sempre aparecem imediatamente. A aquisição de algumas formas de conhecimento nem sempre conduz à criação de indicadores empíricos. Estas questões sugerem a necessidade de indicadores alternativos de desempenho e de retorno sobre o investimento para as atividades de aprendizado. Existe, atualmente, muito de experimentação na criação de novos indicadores para as atividades de aprendizado, de investimentos e de "insumos" (inputs), assim como a relação desses indicadores com resultados mensuráveis (outcomes). Existe algum debate, no entanto, sobre como se deve fazer para implementar estes indicadores de forma objetiva, sem impor obstáculos com procedimentos oficiais. Além disso, a bateria de indicadores usados precisa ser suficientemente simples para ser significativa para fins de informação e credibilidade.

O número atual de ferramentas de aprendizado e de técnicas disponíveis é relativamente grande. Em vez de tentar proporcionar um inventário detalhado, pode ser mais frutífero analisar mais detidamente a tentativa de um serviço público de criar uma organização de aprendizagem: a abordagem do serviço público do Canadá.

\section{A abordagem canadense na criação de uma organização de aprendizagem para o serviço público}

\section{Uma visão histórica}

As raízes históricas do aprendizado são profundas no serviço público do Canadá. Durante o período entre 1857 e 1908, houve uma série de iniciativas para criar um serviço público altamente profissional que atraísse 
os melhores e mais brilhantes graduados universitários (Heintzman, 1997).

Durante a maior parte do século XX, estruturas institucionais foram estabelecidas para desenvolver mais ainda as habilidades dos servidores públicos, incluindo o estabelecimento de um amplo sistema de treinamento nas línguas oficiais (1963-68) e um centro de desenvolvimento profissional e de pesquisa administrativa, o Canadian Centre for Management Development - CCMD (Centro Canadense para o Desenvolvimento da Gestão) 1991. Foi esta forte fundação que ajudou a tornar o serviço público do Canadá uma das fontes mais duradouras de análise e de obtenção de recomendações para os especialistas.

O serviço público canadense também esteve entre os primeiros a projetar a idéia de aprendizado organizacional. Do final dos anos 60 ao começo dos anos 70, estas idéias foram usadas para redesenhar as estruturas centrais de governo visando usar o máximo do conhecimento relacionado à política (Aucoin e French, 1974: 14-15; Aucoin, 2000: 18). Estas primeiras experiências condicionaram o serviço público a procurar novos caminhos para utilizar o poder do conhecimento dentro de seus principais processos.

A recente onda de interesse na criação de organizações de aprendizagem começou com a iniciativa PS 2000 (1989-90). Este conjunto de reformas procurou revigorar o sistema de pessoal e, através de consultas ao setor privado, identificou o aprendizado contínuo e o desenvolvimento de competências como prioridades fundamentais.

O desenvolvimento da competência foi explorado pela primeira vez através de um perfil de características de liderança redigido por duas agências centrais do governo canadense (Canadá, 1990). Passou-se então a procurar essas características que dessem suporte ao desempenho efetivo dos gerentes, independentemente de suas funções ou níveis gerenciais. Uma lista mais detalhada de características foi criada sob os auspícios do Competency-based Human Resource Management Action Group (Grupo de Ação da Administração dos Recursos Humanos baseado em Competência) 1996. O Wholistic Competency Profile (Perfil de Competência Holístico) que resultou deste trabalho, tratava as características individuais e o contexto organizacional de uma maneira holística, incluindo uma análise das competências físicas (por exemplo a resistência física), dos estilos, os traços de personalidades e os interesses e valores (Slivinski e Miles, 1996). Este perfil ainda é usado como uma ferramenta de avaliação de desempenho e de desenvolvimento de carreira. Também foi integrada a uma estrutura de administração superior para melhorar o desempenho de pessoal (Canadá, 1999). Várias instituições públicas e companhias privadas adotaram esta abordagem ao desenvolvimento humano, e este modelo continua sendo um dos mais profundos e amplamente usados. 
Enquanto isto, o serviço público canadense também estava observando atentamente o potencial do aprendizado organizacional. O CCMD foi escolhido para identificar as características principais de uma organização de aprendizagem (Canadá, 1994). No ano seguinte, a iniciativa do Program Review (Revisão de Programas) 1995 implementou uma série de medidas de austeridade fiscal e projetou um novo padrão para regular a disciplina financeira. Como conseqüência, foi lançada a La Relève Task Force (Força Tarefa La Relève), para encontrar formas novas e inovadoras de revigorar o serviço público. Uma ampla variedade de iniciativas de aprendizado foi lançada, incluindo a Leadership Network (Rede de Liderança) para promover o aprendizado gerencial e oportunidades de desenvolvimento. Vários ministérios e unidades de governo seguiram esta linha, lançando seus próprios projetos piloto e iniciativas de aprendizado. Isto inclui o Interdepartmental Knowledge Management Forum (Fórum Interministerial de Gestão do Conhecimento), uma comunidade de práticas projetada para compartilhar idéias sobre o aproveitamento máximo do conhecimento contido no serviço público.

Os anos 90 presenciaram o desenvolvimento de uma infra-estrutura mais detalhada e integrada de informação eletrônica e de comunicações. O cargo de funcionário chefe da informação foi criado para inspecionar o desenvolvimento desta infra-estrutura tecnológica. Isto evoluiu para uma iniciativa de governo online mais centrada no cidadão, que procura alavancar o poder da tecnologia para promover uma maior conectividade com o cidadão.

No final da década, havia a necessidade de se promover maior união destas linhas em uma estratégia mais coerente e encontrar novos meios de expandir qualquer lição aprendida. O Deputy Ministers Learning and Development Committee (Comitê dos Vice-ministros para o Aprendizado e o Desenvolvimento) 2000 foi formado para projetar uma estratégia geral. O comitê projetou uma estrutura conceitual e 44 recomendações específicas para transformar todo o serviço público em uma organização de aprendizagem. O CCMD também iniciou uma série de "pesquisas de ação" para oferecer, aos gerentes, conselhos práticos sobre como promover o aprendizado dentro de suas organizações.

Embora esta cronologia diga muito sobre a magnitude do compromisso do serviço público canadense com o aprendizado, ela proporciona poucos detalhes sobre a substância efetiva de sua abordagem. Passamos agora a uma análise dos pontos principais do modelo canadense.

\section{A estratégia geral}

Antes de descrever o modelo do serviço público canadense, algumas advertências são necessárias. O impulso para criar uma organização de 
aprendizagem não é uma iniciativa monolítica, mas um conjunto de ini-

ciativas, de redes e de atividades localizadas, esparsamente ligadas, todas elas orientadas por projetos mais abrangentes e fontes de recursos amplamente acessíveis. A organização de aprendizagem também é um trabalho em curso, com novos experimentos e iniciativas que surgem de forma constante. Finalmente, embora este modelo seja apresentado como algo novo, em vários aspectos o serviço público canadense sempre operou como uma organização de aprendizagem.

A criação de uma estratégia de aprendizado para o serviço público foi sustentada por quatro pilares-chave. O primeiro pilar foi a sensibilização para o projeto, que contou com a participação ativa dos funcionários mais antigos. A estratégia foi dirigida por um comitê de vice-ministros e buscava subsídios da ampla comunidade executiva. Isto ajudou a tornar a estratégia consistente com as prioridades em todo o serviço público e reforçou a legitimidade da estratégia. O segundo pilar consiste em um conjunto extenso de consultas com os gerentes públicos de todo o país. Este amplo esforço envolveu mais de 1.000 gerentes de todas as principais regiões do Canadá. Isto ajudou a tornar a estratégia mais relevante nas bases do governo. $\mathrm{O}$ terceiro pilar consistiu de uma pesquisa profunda e no desenvolvimento de políticas. Equipes de pesquisadores levaram em consideração o conhecimento de ponta no assunto e desenvolveram várias idéias práticas. $\mathrm{O}$ último pilar da estratégia foi a proposição de um conjunto de recomendações factíveis. Planos estratégicos freqüentemente soam superficiais porque eles não têm o apoio de ações explícitas e viáveis. Portanto, tornou-se relativamente fácil ver como a implementação e o progresso irão acontecer.

A estratégia preponderante se baseia na noção de que o aprendizado vitalício individual e o aprendizado organizacional coletivo estão intrinsecamente entrelaçados - entrelaçados como a dupla hélice das cadeias do DNA. Esta metáfora percorre os seis atributos de uma organização de aprendizagem que o serviço público canadense procura criar. Estes atributos são os seguintes:

- A organização de aprendizagem promove o aprendizado - o aprendizado não deve ser tratado como uma atividade paralela; isto é, como algo separado das funções "críticas da missão" de uma organização. Ao invés disso, os objetivos organizacionais e as atividades de aprendizado devem ser alinhados de forma que uma organização possa determinar suas deficiências e superá-las. Isto envolve a criação de uma cultura que valorize o aprendizado, proporcionando oportunidades e incentivos para que os indivíduos e os grupos tirem lições de forma aberta e inclusiva.

- Uma organização de aprendizagem aprende com a experiência - a experiência é uma rica fonte de conhecimentos profundos para melhorar o trabalho do serviço público. O serviço público, portanto, precisa ter a capacidade para refletir continuamente sobre a sua experiência, extrair 
lições valiosas, e compartilhar estas lições de forma mais ampla. Isto envolve o desenvolvimento de sistemas, tais como uma moderna tecnologia de informação e infra-estrutura necessária ao gerenciamento, para disseminar as lições extraídas da experiência.

- Uma organização de aprendizagem valoriza as pessoas e a diversidade — a sociedade canadense é extremamente diversa. Esta diversidade é uma fonte de revigoramento quando pessoas com diferentes experiências, habilidades e perspectivas são colocadas juntas para atingir objetivos públicos. Então, o serviço público canadense está reatando com sua experiência histórica bem-sucedida para a construção de um clima de confiança e respeito, visando canalizar esta diversidade para a busca do aprendizado.

- A organização de aprendizagem, integra o aprendizado às práticas administrativas — os gerentes realizam um papel crucial para facilitar o aprendizado. Portanto, conclui-se que o aprendizado deve figurar dentre as prioridades e atividades da gerência. Por exemplo, os ministérios precisam de um aprendizado explícito e de políticas de desenvolvimento, enquanto que os indivíduos e as unidades do governo precisam de planos complementares de aprendizado. Os gerentes também são incentivados a facilitar as necessidades de aprendizado de uma organização proporcionando apoio e recursos para a motivação (por exemplo, tempo e financiamento para o aprendizado).

- Uma organização de aprendizagem aprende para servir — em última análise, o objetivo de integrar o aprendizado aos serviços públicos visa melhor responder às demandas dos cidadãos. O serviço público tem como tarefa a responsabilidade de encontrar novas e melhores práticas para incorporar sistematicamente os subsídios e os retornos do cidadão nas práticas organizacionais.

- Uma organização de aprendizagem avalia os processos e os resultados — é necessária uma reflexão sistemática para se extrair lições. O serviço público está, portanto, redobrando seus esforços para monitorar e revisar seus processos, assim como os resultados de tais processos. Isto também significa examinar a medida na qual os processos contribuem para o aprendizado organizacional (e vice-versa).

Estes seis atributos de uma organização de aprendizagem estão sendo alcançados na medida em que os servidores públicos atuam nas 44 recomendações específicas. As recomendações incluem várias iniciativas inovadoras, compreendendo: o sistema de mentores, que se baseia no conhecimento dos "mais antigos" (servidores públicos mais antigos que se aposentaram, ou que estão próximos da aposentadoria) para preservar a memória corporativa; um fundo para semear a inovação do aprendizado que objetiva financiar projetos que usem o aprendizado para aperfeiçoar questões como a prestação de serviços e o desenvolvimento das políticas; 
e um sistema de fundos portáteis de aprendizado que proporcionem um financiamento para treinamento e desenvolvimento que acompanhe os indivíduos quando eles mudam de área no serviço público.

Embora seja muito cedo para determinar a escala e o alvo da mudança que ocorreu como resultado desta estratégia, o serviço público canadense está sobrecarregado de atividades. Existe uma constelação de iniciativas movendo-se na direção determinada pela estratégia. Talvez seja útil dar uma rápida incursão em alguns planetas mais interessantes desta constelação.

\section{Iniciativas em curso}

Existem quatro grupos particularmente interessantes de iniciativas em curso, que são os seguintes:

- Os líderes no compartilhamento das especialidades do aprendizado - cada ministério e agência possui um único grupo de especialização e de conjunto de responsabilidades. Estas especialidades foram alavancadas usando-se técnicas de aprendizado para criar novas capacidades. O Department of Foreign Affairs and International - DFAIT, (Ministério das Relações Exteriores e do Comércio Internacional), por exemplo, criou um Center for Intercultural Learnig (Centro para o Aprendizado Intercultural). O centro auxilia os servidores públicos a ficarem mais efetivos em suas relações interculturais, ajudando-os a apreciar a diferença cultural e a operar em diferentes contextos. O CCMD combinou sua infra-estrutura tecnológica avançada com seu conhecimento em treinamento para criar o E-learnig Program (Programa de Aprendizado Eletrônico) que facilita o aprendizado à distância.

- Casos exemplares - existe um bom número de grupos que podem ser denominados de "pioneiros" na medida em que eles responderam à solicitação e implementaram técnicas de aprendizado inovadoras. Vários destes casos estão sendo transformados em "histórias de aprendizado", ou em histórias de eventos e de lições aprendidas, relatadas do ponto de vista dos agentes envolvidos. O Council on Administration (Conselho da Administração), uma associação interministerial formada por seis ministérios, desenvolveu uma cultura de aprendizado e equipes de aprendizado enquanto constituía serviços locais de apoio compartilhado serviços que os ministérios, dentro de um local, pudessem compartilhar para reduzir a redundância e aumentar a eficiência. As estórias dos participantes foram registradas em uma história de aprendizado, e esta foi a primeira de seu gênero dentro do serviço público canadense (Canadá, 1998c). Um conjunto similar de histórias está sendo planejado para documentar o progresso na implementação da estratégia de aprendizado do serviço público. As histórias atuais variam de unidades menores a 
ministérios inteiros. Um exemplo disso (unidades menores) é um grupo de consultoria da administração na Industry Canada, que vem implementando uma bateria abrangente de técnicas de aprendizado para reinventar a maneira de oferecerem seus serviços. O outro exemplo é oferecido pela Agriculture Canada, que usou as técnicas (incluindo os processos de aprendizado de equipes tomadoras de decisões e investimentos extensivos em treinamento) para desenvolver políticas que promovam novos produtos agrícolas de alta tecnologia e de maior valor agregado.

- Recursos inovadores para os servidores públicos - uma estratégia em nível corporativo tem melhores chances de sucesso quando reforçada por uma orientação específica para os indivíduos envolvidos. Isto é particularmente importante na criação da organização de aprendizagem, já que vários dos conceitos e técnicas ainda não são amplamente reconhecidos. Foi criada uma série de recursos para os servidores públicos, visando proporcionar uma maior clareza. A Indian Affairs \& Northern Development produziu um livro de bolso rico em técnicas de aprendizado que as equipes podem aplicar em suas agendas de trabalho (Canadá, 1998). As CCMD's Action Research Roundtables (Conferências de Pesquisas de Ação do Centro Canadense para o Desenvolvimento da Gestão $C C M D$ ) criaram um guia mais abrangente que acompanha os indivíduos e as equipes através do processo de criação de uma organização de aprendizagem (Canadá, 2001), assim como um guia que ressalta os aspectos de aprendizado para o gerenciamento de risco (Canadá, 2001b). Para aqueles que desejam uma maior interatividade, o CCMD's Learning Coach (Treinador do Aprendizado do CCMD) é um programa baseado na web que ajuda os servidores públicos a desenvolver planos pessoais de aprendizado. A Transport Canada desenvolveu um mapa de aprendizado para a área de transportes para ajudar os gerentes, em particular, a incorporar um aprendizado contínuo a suas atividades diárias (Canadá, 1998b).

- Redes de aprendizado - a Leadership Network (Rede de Liderança) criou um inventário de redes de mais de 80 pessoas dedicadas a funções governamentais, desafios, área política, interesses ou região. Cada rede compõe-se de grupo de servidores públicos compartilhando idéias de forma concentrada e não hierárquica, e que constroem, neste processo, conexões comunitárias. A Rede de Liderança estuda sistematicamente estas redes, ao mesmo tempo em que oferece a compilação de uma lista das lições aprendidas.

Isto é apenas uma rápida incursão em alguns dos processos que estão sendo implementados na criação de uma organização de aprendizagem. Num futuro não tão distante, evidências mais abrangentes da mudança na maneira como operam os servidores públicos canadenses estarão provavelmente disponíveis. 


\section{Uma rápida incursão no futuro}

Como sugere a análise apresentada no item anterior, a criação da organização de aprendizagem é um trabalho que está em curso, com muitas dimensões interessantes. Consegue-se visualizar melhor o sentido de como o serviço público canadense continuará a evoluir, fazendo-se uma rápida incursão em alguma das novas iniciativas que estão em debate. Ao contrário das iniciativas já apresentadas anteriormente, estas continuam sendo propostas ainda não implementadas. As propostas, contudo, proporcionam alguma noção de como o serviço público está se saindo em seu compromisso.

\section{A política de um serviço público que aprende}

Num esforço contínuo para proporcionar orientação e coerência para impulsionar a criação da organização de aprendizagem, existe um movimento para articular uma política de aprendizado para o serviço público canadense como um todo. Isto iria reforçar ainda mais a abordagem do aprendizado — assinalando a importância do treinamento, do desenvolvimento e do aprendizado - apoiando-a num conjunto de compromissos tangíveis. Isto também iria proporcionar às organizações uma orientação clara e um conjunto de expectativas sobre o que os gerentes públicos são responsáveis por atingir. Ambos são ingredientes cruciais de um regime de responsabilização efetiva.

A política, em si, iria conter vários elementos projetados para melhorar o acesso ao aprendizado e tornar as responsabilidades mais claras. Estes elementos são os seguintes:

- Primeiramente, a política iria possibilitar um aumento nos recursos financeiros disponíveis para o treinamento e o desenvolvimento. Uma meta de financiamento poderia ser estipulada. Por exemplo, o financiamento poderia ser pensado em termos de porcentagem do custo de uma folha de pagamento de um funcionário, ou como um incremento cumulativo no financiamento. A intenção é de assegurar que todos os servidores públicos tenham níveis adequados de recursos para alcançar seus objetivos de aprendizado. O resultado final seria elevar a disponibilidade de recursos para o aprendizado do setor público a um nível que seja comparável ao das organizações líderes no setor privado.

- O segundo elemento da política seria tornar claro quem são os responsáveis pelas atividades de aprendizado. Seria reconhecido que o aprendizado é uma responsabilidade compartilhada entre os indivíduos e os gerentes das organizações. Ainda assim, ao mesmo tempo, cada lado teria um conjunto específico de responsabilidades. Os gerentes seriam 
responsáveis pela garantia do acesso às oportunidades de aprendizado, por exemplo. Cada lado responderia pelo progresso resultante do conjunto de suas respectivas responsabilidades.

- Todos os funcionários permanentes do serviço público seriam chamados a desenvolver um plano de aprendizado que projetasse metas de aprendizado tangíveis. Ao mesmo tempo, os ministérios e as agências seriam requisitados a ter uma política de treinamento, desenvolvimento e de aprendizado. Em muitos casos os ministérios e as agências já dispõem de tais políticas. Esta exigência se tornaria, então, universal, e garantiria que cada política fosse mais abrangente. A política iria articular o compromisso da organização com o aprendizado, como o aprendizado se relaciona com as linhas estratégicas de cada organização, e ficariam claras quais as oportunidades de aprendizado que os funcionários poderiam esperar.

- Para garantir que as organizações sejam responsáveis pelo cumprimento de seus compromissos de aprendizado, faz-se necessária a implementação de mecanismos de prestação de contas. Relatórios anuais sobre o progresso efetuado seriam necessários e, eventualmente, poderia ser necessário um conjunto de indicadores comparáveis e abrangentes. Esta necessidade de prestação de contas serve para disciplinar uma organização e para demonstrar aos líderes políticos o quanto que o aprendizado tornou-se uma prioridade.

Ainda não está claro qual organização poderia ser responsável pela política. Contudo, faria sentido que a inspeção da política de aprendizado fosse integrada a outras atividades de inspeção mais típicas.

\section{Fundos de aprendizado para o serviço público}

Se o serviço público canadense pretende manter seu alto padrão de tratamento igualitário e justo aos indivíduos, ele deve assegurar-se de que todos os funcionários tenham acesso às oportunidades de aprendizado adequadas às suas necessidades. Atualmente, o acesso aos programas formais de aprendizado é, de certo modo, desigual entre as organizações e as funções do serviço público.

Em termos ideais, os servidores públicos deveriam ser livres para vivenciar experiências de trabalho em um conjunto representativo de organizações do serviço público. Isto significa desfazer-se de obstáculos à mobilidade. Tais obstáculos impedem um acesso justo ao financiamento do aprendizado nas organizações. Um indivíduo pode não querer assumir um cargo que the seja mais adequado, se existirem menores oportunidades de aprendizado ligadas a este cargo. Além disso, a mobilidade dentro do serviço público tem o benefício adicional de expor os indivíduos a novas experiências e a novas pessoas - elementos importantes do aprendizado organizacional em seu amplo sentido. 
Por estas razões, o serviço público canadense está explorando a

possibilidade de criar fundos de aprendizado individuais. Estes fundos iriam outorgar uma quantidade específica de recursos para que os indivíduos busquem as oportunidades de aprendizado. Os recursos viriam sob duas formas: financiamento para comprar serviços de aprendizado, e tempo disponível fora das tarefas do trabalho normal para participar de atividades formais de aprendizado. Os fundos seriam portáteis; ou seja, eles iriam seguir o indivíduo caso ele ou ela mudasse de cargo (ou mudasse para outra organização) dentro do serviço público.

Isto também estaria ligado ao aumento de financiamento mencionado anteriormente. Isto não significa, contudo, que os fundos de aprendizado representem um maior aumento de custo. De certo modo, eles tenderão a criar poupança se implementados de forma adequada. Menos tempo seria gasto na busca de recursos escassos para a participação no aprendizado formal. O maior número de pessoas partici pando de programas de aprendizado permite aos prestadores de serviços economias de escala. Também a redução de barreiras à mobilidade melhora a eficiência de alocação de mercados de trabalho internos dentro do serviço público.

\section{Fundo para semear a inovação do aprendizado}

Até agora, nossa breve incursão no futuro focalizou-se no aprendizado individual. Embora seja verdade que estas iniciativas poderiam contribuir para o desenvolvimento de uma cultura do aprendizado, existe uma necessidade de se apoiar o aprendizado organizacional de forma específica. Isto envolve o desenvolvimento de novas capacidades organizacionais e de inovações que promovam experimentação, colaboração e reação por parte dos canadenses. Isto é um desafio, porque este desenvolvimento não pode ser simplesmente uma obrigação. Existe uma necessidade de se promover um apoio à inovação.

Um método possível é o de proporcionar apoio financeiro para incentivar a inovação. Um "fundo para semear a inovação do aprendizado" iria proporcionar "capital de risco" (por falta de um termo melhor) para as unidades que desejassem implementar projetos inovadores, mas que fossem do tipo capital intensivo. Este fundo iria proporcionar uma medida de proteção para aqueles que estão se empenhando na experimentação, já que a "tentativa e erro" na implementação de uma nova experiência não poria em risco recursos vitais para a missão da organização. Certamente um número expressivo de iniciativas de grande valor para os cidadãos poderia resultar dessas experiências. 
Este fundo poderia começar como um projeto piloto. $\mathrm{O}$ financiamento seria outorgado por uma comissão composta por membros de diversos cargos e com diversos históricos, incluindo indivíduos de fora do serviço público.

\section{A convergência do aprendizado e da tecnologia}

A informação e as tecnologias de comunicação permeiam muitos aspectos da vida organizacional. Isto pode trazer vários benefícios, incluindo novas capacidades e novas eficiências. A transição, contudo, não aconteceu sem suas deficiências. A tecnologia pode ser um aspecto frustrante do trabalho porque ela requer, freqüentemente, que os indivíduos e que as organizações se moldem às necessidades das máquinas, ao invés de ocorrer o contrário.

Estamos, atualmente, entrando num estágio do desenvolvimento tecnológico que permite adequar a tecnologia às necessidades humanas. Com servidores públicos mais ativamente envolvidos na aplicação da tecnologia em seus ambientes de trabalho, a tecnologia se torna mais integrada às operações-chave de uma organização. $\mathrm{O}$ crescimento da capacidade tecnológica, tal como o maior uso de vídeo e áudio, também abriu novas oportunidades para se promover o aprendizado.

Um exemplo dessa oportunidade é a criação de um glass desktop dentro de cada "estação de trabalho" no interior do serviço público, ou seja, computadores que oferecem o acesso instantâneo à informação e ao conhecimento requerido para a tomada de decisões. Os servidores públicos terão a informação e o conhecimento de que precisam a seu alcance, superando a "sobrecarga de informação" do processo. As novas redes, mais específicas e confiáveis, e a utilização de novos programas de gestão do conhecimento, estão melhorando a qualidade das informações, tornandoas mais úteis e valiosas para as organizações.

Isto também proporciona novas oportunidades de aprendizado eletrônico. Aumentar o fluxo de vídeo e áudio pela Internet, diálogos online, ferramentas de acesso à Internet, e informações sobre cursos continuamente atualizadas, proporcionam novas oportunidades. Um aspecto relevante é não rebuscar muito os cursos de aprendizado à distância, para que um grande número de servidores públicos possa fazer treinamento a partir de seus locais de trabalho, minimizando, assim, a quantidade de tempo fora do trabalho.

\section{Conclusão}

Este artigo proporcionou uma revisão do que é uma organização de aprendizagem e de como o serviço público canadense está desenvolvendo 
um exemplo particularmente inovador. Fica claro que a criação de uma organização de aprendizagem não é simplesmente uma opção, mas uma necessidade urgente em decorrência das mudanças em curso no ambiente de governo e no ambiente de trabalho moderno.

Estes são passos preliminares de uma jornada mais longa e recompensadora. Apesar disto, alguns fatores que contribuem para o sucesso já estão claros. Primeiro, a organização de aprendizagem não pode ser criada sem um impulso planejado para melhorar tanto o aprendizado individual contínuo quanto um aprendizado organizacional mais amplo. Ambos os lados desta equação são mutuamente dependentes e reforçadores. Segundo, esta abordagem não pode simplesmente ser comandada e "difundida" de cima para baixo. A organização de aprendizagem é criada através da iniciativa dos servidores públicos em todos os níveis da hierarquia do serviço público. Os que estão no topo têm que projetar uma estratégia corporativa e proporcionar aos servidores públicos os recursos necessários. Os gerentes facilitam o processo em nível básico, através de técnicas integradas de aprendizado introduzidas na vida quotidiana de sua organização. Cada servidor público torna-se responsável pelo seu próprio desenvolvimento intelectual e trabalha para recrutar outros para a causa do aprendizado.

\section{| Notas}

* () Canadian Centre for Management Development, The Public Service of Canada's Approach to the Learning Organization, 2001.

All rights reserved. This publication has been reproduced and translated with the permission of the Minister of Public Works and Government Services (2001), Ottawa, Ontario K1A 0S5 Canada.

(C) Centre Canadien de Gestion, La Fonction Publique du Canada et le Concept de l'Organisation Apprenante, 2001.

Tous droits réservés. Cette publication a été reproduite et traduite avec la permission du Ministre des Travaux Publics et Services Gouvernementaux, (2001), Ottawa, Ontario K1A 0S5 Canada.

(C) ENAP Escola Nacional de Administração Pública, Canadá: organizações de aprendizagem no setor público, 2001.

Todos os direitos reservados. Esta publicação foi reproduzida e traduzida com permissão do Ministério de Trabalhos Públicos e Serviços do Governo (2001), Ottawa, Ontario K1A 0S5 Canadá.

1 Desejamos ressaltar a contribuição de Peter Stoyko, do $C C M D$, na elaboração deste documento. 


\section{Referências bibliográficas}

Australian National Audit Office. (1997), "Financial Control and Administration Audit Across Agencies". Audit Report 39, ANAO.

BARRET, P.J. (2000), "Managing Compliance for Assurance and Performance: Setting the Course - Integrating Conformance with Performance". Speach by the Auditor-General for Australia.

Department of Finance and Administration. "Atorney-General's Department; Australian Competition and Consumer Comission". Joint Seminar, Canberra: ANAO website.

Controller and Auditor-General.(1999), "Government Departments". Results of the 1998-99 Audits. Wellington, OAG.

. (1999), "Third Report for 1999: The Accountability of Executive

Government to Parliament". Wellington, OAG.

Department of Finance. (1992), The Role of Evaluation in Decision Making in the 199192 Budget Context. Canberra, Department of Finance.

. (1994), The Use of Evaluation in Decision Making in the 1993-94

Budget. Canberra, Department of Finance.

. (1995), The Use of Evaluation in Decision Making in the 1994-95

Budget. Canberra, Department of Finance.

Department of Finance and Administration. (1998), "Specifying Outcomes and Outputs". Canberra, DOFA - Budget Group.

. (1999), "Outcomes and Outputs". Canberra, DOFA — Budget Group.

General Accounting Office (USA). (1999), Managing for Results - Opportunities for Continued Improvements in Agencies 'Performance Plans. Washington, DC, General Accounting Office (USA).

Joint Committee of PublicAccounts and Audit. (2000), Review of the financial Management and Accountability Act 1997 and the Commonwealth Authorities and Companies Act 1997. Canberra, Parliament.

National Partnership for Reiventing Government. (1999), Balancing Measures: Best Practices in Performance Management. Washington. DC, National Partnership for Reiventing Government (USA).

Neale, A., D AKen, L. (2000), Streamlining Non-Financial Performance Reporting. Public Sector Performance 2000. Wellington, New Zealand.

OECD-PUMA. (1996), Performance Auditing and the Modernisation of Government. Paris, OECD.

Paris, OECD.

Office of Auditor-general. (2000), Roles and Functions of the OAG. Wellington, OAG.

Pollit, C., Bouckaert, G. (2000). Public Management Reform - A Comparative Analysis. Oxford., Oxford University Press.

President of the Treasury Board (Canada). (1999), “Managing for Results 1999”, vol. 1. Ottawa, TBS.

SARPetta, S., Bassanini, et al. (2000), Economic Growth in the OECD Area - Recent Trends at the Aggregate and Sector Level. Paris, OECD.

Senate Finance and Public Administration Legislation Committee. (2000), The Format of the Portfolio Budget Statements. Canberra, Parliament.

Swedish Agency forAdministrative Development. (1999), The Swedish Central Government in Transition 1999. Stockolm, Statskontoret.

Swedish National Audit Office (RRV). (1999), Handbook in Performance Auditing Theory and Practice, $2^{\text {nd }}$ ed. Stockolm, Ruksrevisionsverket (RRV). 


\section{Canadá: organizações de aprendizagem no setor público \\ Centro Canadense para o Desenvolvimento da Gestão (CCMD)}

$\mathrm{O}$ artigo apresenta uma discussão das diversas dimensões que compõem uma "organização de aprendizagem", a partir da recomposição dos principais aspectos estabelecidos por teóricos das organizações sobre os temas da gestão do conhecimento e de como as organizações se adaptam e/ou inovam em situações de mudança e desafio. Apresenta também a abordagem canadense de organizações de aprendizagem, descrevendo as principais iniciativas adotadas na implementação prática desta concepção. Mostra as principais lições aprendidas no processo de implementação da concepção canadense de organizações de aprendizagem no setor público,apresentando tal implementação como uma ação imperiosa, estabelecida não por desejos individuais, mas pelas profundas mudanças que estão ocorrendo nos ambientes operacionais das organizações públicas.

\section{Canadá: organizaciones de aprendizaje en el sector público \\ Centro Canadense para el Desarrollo de la Gestión (CCMD)}

El artículo presenta una discusión de las diversas dimensiones que componen una "organización de aprendizaje", a partir de la recomposición de los principales aspectos establecidos por teóricos de las organizaciones sobre los temas de la gestión del conocimiento y de como las organizaciones se adaptan e/o inovan en situaciones de cambio y desafío. Presenta también el abordaje canadense de organizaciones de aprendizaje, describiendo las principales iniciativas adoptadas en la implementación práctica de esta concepción. Exhibe las principales lecciones aprendidas en el proceso de implementación de la concepción canadense de organizaciones de aprendizaje en el sector público, presentando esta implementación como una acción imperiosa, establecida non por deseos individuales, pero por los profundos cambios que están ocurriendo en los ambientes operacionales de las organizaciones públicas.

\section{Canada: learning organizations in the public sector \\ Canadian Centre for Management Development (CCMD)}

The article presents a discussion about the diverse dimensions that compose the "learning organization". It starts from resetting the main aspects established by organization theoriticians on the subjects of knowledge management and the way organizations adapt and/or innovate in situations of change and challenge. It also presents the Canadian approach to learning organization, describing the main initiatives adopted on the practical implementation of this concept.

It points out the main lessons learned in the implementation process of the Canadian concept of learning organization in the public sector. It also presents the implementation as an imperious action established by deep changes which are taking place within operational environments of public organizations, rather than by individual desires.
Ano 52

Número 3

Jul-Set 2001

Centro

Canadense

para o

Desenvolvimento

da Gestão,

Otawa, Canadá. 